\title{
Early risk warning system for distant metastasis of hepatitis B virus-associated hepatocellular carcinoma with portal vein tumor thrombus
}

\author{
MENGGE LI $^{1,2^{*}}$, YALIN ZHAO ${ }^{3 *}$, XIAOLI LIU ${ }^{1 *}$, SHUAN ZHANG ${ }^{1}$, YUYONG JIANG ${ }^{1}$ and ZHIYUN YANG ${ }^{1}$ \\ ${ }^{1}$ Center for Integrative Medicine, Beijing Ditan Hospital, Capital Medical University, Beijing 100015; ${ }^{2}$ Department of \\ Hepatobiliary Spleen and Stomach, Henan Province Hosptial of Traditional Chinese Medicine, Zhengzhou, Henan 450002; \\ ${ }^{3}$ Department of Gastroenterology and Hematology Medicine, People's Hospital of Hebi, Hebi, Henan 450000, P.R. China
}

Received August 14, 2018; Accepted June 7, 2019

DOI: $10.3892 / \mathrm{ol} .2020 .11423$

\begin{abstract}
Portal vein tumor thrombus (PVTT) promotes distant metastasis of hepatocellular carcinoma (HCC), which increases the mortality of patients with HCC and PVTT. The aim of the present study was to develop an early risk warning system for distant metastasis of hepatitis B virus (HBV)-associated primary HCC (HBV-HCC) with PVTT. Data from 346 patients (263 and 83 in the modeling and validation cohorts, respectively) who had received primary diagnoses of HBV-HCC and PVTT between January 2012 and June 2015 at Beijing Ditan Hospital (Beijing, China) were retrospectively examined. In the modeling cohort, univariate and multivariate logistic regression analyses were conducted to determine the factors that were significantly associated with distant metastasis. Furthermore, an early risk warning model for distant metastasis was proposed and validated through receiver operating characteristic curve analysis in the validation cohort. The results revealed that neutrophil to lymphocyte ratios of $\geq 2.31$, red blood cell counts of $\geq 4.07 \times 10^{12}$ cells $/ 1$, C-reactive protein levels of $\geq 7.02 \mathrm{mg} / 1$, aspartate aminotransferase levels of $\geq 118.5 \mathrm{U} / 1$ and tumor thrombus site (at branch) were significantly positively associated with distant metastasis of HBV-HCC with PVTT $(\mathrm{P}<0.05$; odds ratio $>1.000)$. A formula for predicting distant metastasis was obtained with an accuracy of $\sim 70 \%$. The results of the present study may allow for the early prediction of distant metastasis and facilitate the administration of appropriate treatment to improve
\end{abstract}

Correspondence to: Professor Zhiyun Yang, Center for Integrative Medicine, Beijing Ditan Hospital, Capital Medical University, 8 Jingshun East Street, Chaoyang, Beijing 100015, P.R. China E-mail: yangzhiyun2016@163.com

*Contributed equally

Key words: hepatitis B virus, primary hepatocellular carcinoma, portal vein tumor thrombus, distant metastasis, risk warning model the outcomes and prognosis of patients with intermediate to advanced HCC.

\section{Introduction}

Liver cancer, mainly hepatocellular carcinoma (HCC), is one of the major causes of cancer mortality worldwide (1). A recent international survey estimated that 841,080 new cases of liver cancer and 781,631 liver-cancer-related mortalities occurred worldwide in 2018; notably, during the same period China alone accounted for approximately one-half of the total number of new cases and mortalities (1). In China, the prevalence of hepatitis B virus (HBV) infection between 2005 and 2006 was $>7 \%$ in the entire population, and $>80 \%$ of all cases of primary liver cancer were reportedly caused by chronic HBV infection (2,3).

Owing to the development of various detection techniques, the prognosis for liver cancer has improved considerably; however, the improvement has been limited as liver cancer progresses rapidly and is frequently detected in the intermediate or advanced stage with portal vein tumor thrombus (PVTT) or distant (extrahepatic) metastasis (4). Distant metastasis, commonly observed in intermediate to advanced stage HCC, severely worsens the prognosis; consequently, survival in patients with HCC and metastasis is significantly shorter compared with that in patients with HCC without metastasis (5-7). During progression, liver cancer commonly invades the portal veins to form PVTT; the incidence rate of PVTT is 44.0-62.2\% (8). Studies have reported that the presence of PVTT is an independent predictor of distant metastasis and promotes distant metastasis of HCC (5-7). Therefore, the mortality rates in patients with $\mathrm{HCC}$ and PVTT are considerably higher compared with those without PVTT. The prognosis is particularly poor in patients with HCC-PVTT and metastasis (9). Accurately predicting the metastasis of HCC with PVTT is crucial for improving treatment outcomes and prognosis; however, to the best of our knowledge, studies on HCC with PVTT metastasis prediction are not currently available.

In the present study, independent risk factors for distant metastasis of HCC with PVTT were identified to develop an 
early risk warning system for distant metastasis. The results of this study may facilitate early prediction and appropriate treatment of distant metastasis of HBV-HCC with PVTT to improve the prognosis of patients with intermediate and advanced HCC.

\section{Materials and methods}

Patients. Data for 182 patients who had received primary diagnoses of HBV-HCC and PVTT and did not exhibit distant metastasis (non-distant metastasis group), and 81 patients who had received diagnoses of HBV-HCC, PVTT and distant metastasis (distant metastasis group) between January 2012 and December 2014 at Beijing Ditan Hospital, Capital Medical University (Beijing, China), were retrospectively examined. In addition, data for 83 patients who had received primary diagnoses of HBV-HCC and PVTT between January 2015 and June 2015 at the same hospital (validation cohort) were also examined. Patients were included if they were 18-85 years old and had received diagnoses of HBV-HCC and PVTT with vascular invasion. Patients were excluded if they exhibited HBV-HCC and PVTT with hepatitis A, C, D or E virus infection or non-hepatitis virus infection, severe diseases (with functional insufficiency) of vital organs (e.g. the heart, lung, kidney, brain or blood), severe mental illness or metastatic HCC, or had incomplete clinical information. This study was approved by the Ethics Committee of Beijing Ditan Hospital, Capital Medical University. As this study was retrospective, informed consent was not required from the patients.

\section{Diagnosis}

$H B V$ infection. According to the Prevention and Treatment Guidelines of Hepatitis B (Version Year 2000) (5,10), patients with a history of hepatitis $\mathrm{B}$, those who tested positive for hepatitis B surface antigen (HBsAg) for $>6$ months, and those who continued to test positive for HBsAg and/or HBV DNA were considered to exhibit a chronic HBV infection.

Primary HCC. Primary HCC was determined through histological and radiological examination. In accordance with the gold standard, specimens of surgically resected liver-occupying lesions and metastatic lesions were examined histologically. According to the radiological diagnosis standard for HCC (5), the patients whose CT images showed vessel intake of contrast agent during the arterial phase, vessel loss during the venous phase and advanced phase, and nodes with a diameter $>2 \mathrm{~cm}$ were considered to exhibit HCC based on the results of a single radiological examination. However, if the diameter of the nodes was $1-2 \mathrm{~cm}$, the patients were considered to exhibit HCC only when the results of two radiological examinations were consistent (6).

PVTT. The presence of PVTT was determined by assessing the filling defect of the portal trunk or branch, which was determined using ultrasound $\mathrm{B}$, computed tomography (CT), magnetic resonance imaging (MRI) or digital subtraction angiography (DSA) examination. Ultrasound examination identified abnormal echo filling (including hypoecho, isoecho, hyperecho and mixed echo) in the entire portal vein, widening of the inner diameter of the portal vein or interruption of blood signals. CT examination indicated widened portal veins with uneven inner density and filling defects, and enhanced CT scans revealed tumor thrombus shadows with low density but without enhancement by plain scanning. MRI scans demonstrated a high signal shadow of the portal vein. DSA reports revealed filling defects, total interruption and widening of the portal vein.

Distant metastasis. Patients with distant metastatic lesions in the lung, lymph nodes, kidney and adrenal gland detected through ultrasound $\mathrm{B}, \mathrm{CT}$ or MRI examination were considered to exhibit distant metastasis.

Statistical analysis. Clinical characteristics (including age, sex, tumor multiplicity and thrombus site), blood parameters [red blood cell (RBC) count, neutrophil to lymphocyte (N/L) ratio, platelet count and platelet/lymphocyte $(\mathrm{P} / \mathrm{L})$ ratio], hepatic and kidney function parameters [levels of aspartate aminotransferase (AST), $\gamma$-glutamyl transpeptidase (GGT), alkaline phosphatase (ALP), direct bilirubin and creatinine $(\mathrm{Cr})$, as well as albumin/globulin $(\mathrm{A} / \mathrm{G})$ ratio], the thrombin function parameter prothrombin activity (PTA), the HCC indicator $\alpha$-fetoprotein (AFP), levels of lactate dehydrogenase $(\mathrm{LDH})$ and $\mathrm{C}$-reactive protein (CRP) were reviewed. Data were analyzed using SPSS 20.0 software (IBM Corp.). Data with a normal distribution are expressed as the mean \pm standard deviation and were compared between the metastasis and non-metastasis groups in the modeling cohort using Student's t-test. Data with abnormal distributions are expressed as the median \pm interquartile range and compared between the two groups by using the rank sum test. Enumeration data are expressed as a frequency, and between-group comparisons were conducted using the $\chi^{2}$ test. $\mathrm{P}<0.05$ was considered to indicate a statistically significant difference.

Variables with $\mathrm{P}<0.05$ in the aforementioned comparisons and those with high clinical significance in the modeling cohort were included in a multivariate logistic regression analysis. Variables that were significantly associated with distant metastasis were determined, and regression coefficients were calculated. Thus, a prediction model for distant metastasis was developed. The prediction accuracy, specificity, sensitivity, false-positive and false-negative values were determined by receiver operating characteristic (ROC) curve analysis. For each value mentioned above, only a single value instead of the mean \pm standard derivation is presented, and statistical comparisons between the data for ROC curves were not performed. To validate this model, the patients from both the modeling and validation cohorts were assessed for the presence or absence of distant metastasis using the aforementioned developed model, which was verified by the clinical data.

\section{Results}

Patient basic characteristics. Data from 263 patients who had received primary diagnoses of HBV-HCC and PVTT (modeling cohort) were retrospectively reviewed for the development of a prediction model for distant metastasis. Among them, 81 patients exhibited distant metastasis (metastasis group), whereas 182 patients did not exhibit distant metastasis (non-metastasis group). In addition, data from 83 patients with 


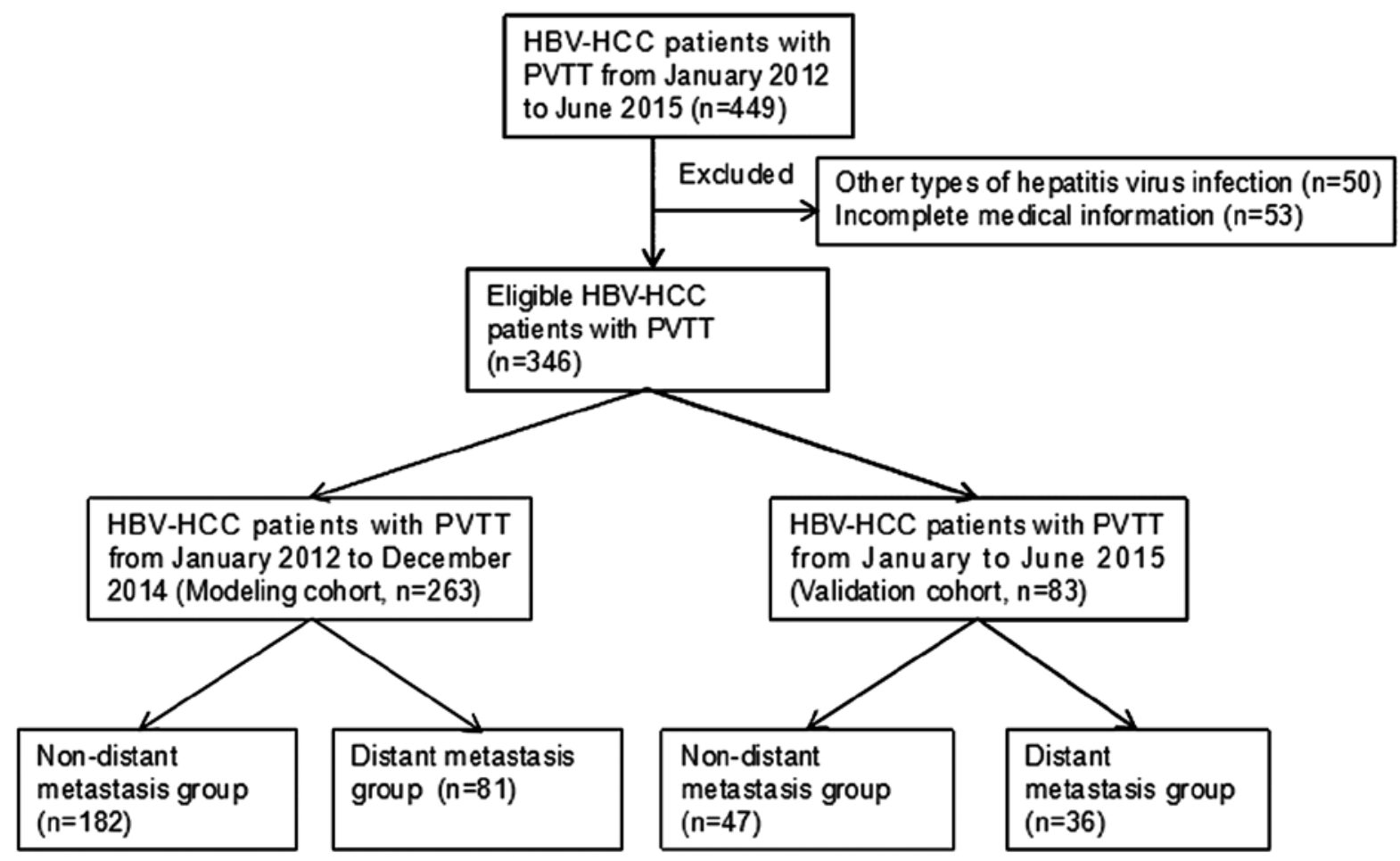

Figure 1. Patients in the modeling and validation cohorts. HBV-HCC, hepatitis B virus-associated primary hepatocellular carcinoma; PVTT, portal vein tumor thrombus.

HBV-HCC and PVTT (comprising 47 patients without metastasis and 36 patients with metastasis) were reviewed for the independent validation of the developed model (Fig. 1).

Establishment of the prediction model of distant metastasis. In the modeling cohort, the metastasis and non-metastasis groups differed significantly in tumor thrombus site, blood platelet count, RBC count, $\mathrm{P} / \mathrm{L}$ ratio, AST level, A/G ratio, GGT, LDH, ALP, CRP and PTA level $(\mathrm{P}<0.05$; Table I). Variables with $\mathrm{P}<0.2$ after univariate analysis were included in the multivariate logistic analysis. Since an increase in the N/L ratio is related to the progression and metastasis of liver cancer (11-13) and serum AFP level is a biomarker for liver cancer, N/L and AFP with $P>0.05$ after univariate analysis were also included in the multivariate analysis. The results demonstrated that $\mathrm{N} / \mathrm{L}$ ratio $\geq 2.31, \mathrm{RBC}$ count $\geq 4.07 \times 10^{12}$ cells $/$ l, CRP level $\geq 7.02 \mathrm{mg} / \mathrm{l}$, AST level $\geq 118.5 \mathrm{U} / 1$ and tumor thrombus site at branch were significantly associated with distant metastasis of HBV-HCC and PVTT ( $\mathrm{P}<0.05$; odds ratio $>1.00$; Table II).

Regression analysis was conducted to further assess the factors associated with distant metastasis. Regression coefficients were calculated for the analyzed factors (Table II). In addition, based on the aforementioned regression analysis of these association factors, the following formula was proposed to predict distant metastasis: $\mathrm{Y}=-5.276+1.711 \times \mathrm{CRP}(\mathrm{mg} / \mathrm{l})$ $+1.312 \times \mathrm{RBC}\left(\times 10^{12}\right.$ cells $\left./ \mathrm{l}\right)+1.192 \times \mathrm{N} / \mathrm{L}+0.912 \times$ AST $(\mathrm{U} / \mathrm{l})+0.553 \times$ tumor thrombus site (branch, assignment of 1 ). The threshold value was -1.05 . To assess the formula for the prediction of distant metastasis, ROC analysis was conducted. An area under the ROC curve (AUC) of 0.731 (95\% CI, $0.649-0.776$ ), Youden's index of 0.3247 , sensitivity of $72.88 \%$, specificity of $59.55 \%$, false-positive value of $40.45 \%$ and false-negative value of $27.12 \%$ were obtained (Fig. 2). In addition, the prediction efficacy of the model [determined using a combination of five factors: N/L ratio, RBC count, tumor thrombus site (branch, assignment of 1), AST level and CRP level] was higher compared with that of any individual factor. The AUC (representing accuracy) and sensitivity of the model were higher compared with those of the individual factors, although the specificity of the model was lower compared with that of the individual factors (Table III; Fig. 2).

Validation of the prediction model of distant metastasis. To validate the established model, the data of the 83 patients (47 non-metastasis and 36 metastasis patients) with HBV-HCC and PVTT in the validation cohort were reviewed. The results of ROC curve analysis revealed an AUC of 0.695 (95\% CI, $0.584-0.791$ ), sensitivity of $65.71 \%$, specificity of $68.75 \%$, false-positive value of $31.25 \%$ and false-negative value of $34.29 \%$ in the validation cohort (Table IV; Fig. 3). At $Y \leq-1.05$, the percentages of patients with metastasis in the model and validation cohorts were 27.10 and $31.40 \%$, respectively, whereas at $Y>-1.05$, the percentages of patients with metastasis increased significantly (72.90 and 68.60\% in the modeling and validation cohorts, respectively; Fig. 4).

\section{Discussion}

HCC commonly invades portal veins and causes PVTT with an incidence of $44.0-62.2 \%$ (2). PVTT promotes the metastasis of HCC (14). If not treated urgently, patients with HCC with PVTT exhibit a median survival time of only 2.7-4.0 months; in addition, mortality in patients with PVTT is considerably higher compared with that in patients without PVTT $(10,15,16)$. 
Table I. Comparison between distant and non-distant metastasis groups.

\begin{tabular}{|c|c|c|c|}
\hline Variables & $\begin{array}{l}\text { Non-distant metastasis } \\
\text { group }(\mathrm{n}=182)\end{array}$ & $\begin{array}{l}\text { Distant metastasis } \\
\text { group }(\mathrm{n}=81)\end{array}$ & P-value \\
\hline Age, years & $55.53 \pm 10.16$ & $54.98 \pm 12.17$ & 0.703 \\
\hline Sex & & & 0.702 \\
\hline Male, n (\%) & $155(85.2)$ & $71(87.7)$ & \\
\hline Female, n (\%) & $27(14.8)$ & $10(12.3)$ & \\
\hline Tumor multiplicity (single/multiple) & $127 / 55$ & $60 / 21$ & 0.478 \\
\hline Tumor thrombus site & & & $0.013^{\mathrm{a}}$ \\
\hline Branch, n (\%) & 68 (37.4) & $46(56.8)$ & \\
\hline Unilateral, $\mathrm{n}$ & 66 & 37 & \\
\hline Bilateral, $\mathrm{n}$ & 2 & 9 & \\
\hline Trunk, n (\%) & $26(14.3)$ & $7(8.6)$ & \\
\hline Branch + trunk, $\mathrm{n}(\%)$ & $88(48.3)$ & $28(34.6)$ & \\
\hline Blood platelet count $\left(\times 10^{9}\right.$ cells/l), M (IQR) & $94.30(70.68-143.38)$ & $108.75(78.90-189.90)$ & $0.041^{\mathrm{a}}$ \\
\hline \multicolumn{4}{|l|}{ RBC count, $\times 10^{12}$ cells $/ 1$} \\
\hline$<4.07, \mathrm{n}(\%)$ & $124(68.1)$ & $39(50.0)$ & $0.006^{\mathrm{a}}$ \\
\hline$\geq 4.07, \mathrm{n}(\%)$ & $58(31.9)$ & $39(50.0)$ & \\
\hline \multicolumn{4}{|l|}{$\mathrm{N} / \mathrm{L}$ ratio } \\
\hline$<2.31, \mathrm{n}(\%)$ & $47(25.8)$ & $14(17.9)$ & 0.170 \\
\hline$\geq 2.31, \mathrm{n}(\%)$ & $135(74.2)$ & $64(82.1)$ & \\
\hline \multicolumn{4}{|l|}{$\mathrm{P} / \mathrm{L}$ ratio } \\
\hline$<3.16, \mathrm{n}(\%)$ & $53(29.1)$ & $10(12.8)$ & $0.005^{\mathrm{a}}$ \\
\hline$\geq 3.16, \mathrm{n}(\%)$ & $129(70.9)$ & $68(87.2)$ & \\
\hline AST (U/l), M (IQR) & $71.10(42.70-106.60)$ & $90.60(54.00-189.40)$ & $0.033^{\mathrm{a}}$ \\
\hline TBIL $(\mu \mathrm{mol} / \mathrm{l}), \mathrm{M}(\mathrm{IQR})$ & $23.55(14.15-43.03)$ & $27.70(16.20-44.90)$ & 0.287 \\
\hline \multicolumn{4}{|l|}{ A/G ratio } \\
\hline$<1.0, \mathrm{n}(\%)$ & $37(20.3)$ & $32(39.5)$ & $0.004^{\mathrm{a}}$ \\
\hline$\geq 1.0, \mathrm{n}(\%)$ & $145(79.7)$ & $49(60.5)$ & \\
\hline GGT (U/l), M (IQR) & $126.15(67.40-249.70)$ & $192.40(115.70-309.70)$ & $0.003^{\mathrm{a}}$ \\
\hline LDH (U/l), M (IQR) & $196.20(162.40-232.10)$ & $211.70(178.10-259.00)$ & $0.020^{\mathrm{a}}$ \\
\hline ALP (U/l), M (IQR) & $131.60(91.40-187.30)$ & $163.40(119.20-245.20)$ & $0.002^{\mathrm{a}}$ \\
\hline Creatinine $(\mu \mathrm{mol} / \mathrm{l}), \mathrm{M}(\mathrm{IQR})$ & $65.00(56.00-75.00)$ & $62.30(56.00-72.00)$ & 0.386 \\
\hline \multicolumn{4}{|l|}{$\mathrm{AFP}, \mu \mathrm{g} / \mathrm{l}$} \\
\hline$<1,000, \mathrm{n}(\%)$ & $93(57.1)$ & $32(45.7)$ & 0.112 \\
\hline$\geq 1,000, \mathrm{n}(\%)$ & $70(42.9)$ & $38(54.3)$ & \\
\hline \multicolumn{4}{|l|}{$\mathrm{CRP}, \mathrm{mg} / \mathrm{l}$} \\
\hline$<7.02, \mathrm{n}(\%)$ & $37(25.3)$ & $4(6.8)$ & $0.003^{\mathrm{a}}$ \\
\hline$\geq 7.02, \mathrm{n}(\%)$ & $109(74.7)$ & $55(93.2)$ & \\
\hline \multicolumn{4}{|l|}{ PTA, $\%$} \\
\hline$<62.55, \mathrm{n}(\%)$ & $46(26.4)$ & $12(14.8)$ & $0.039^{\mathrm{a}}$ \\
\hline$\geq 62.55 \mathrm{~m}, \mathrm{n}(\%)$ & $128(73.6)$ & $69(85.2)$ & \\
\hline
\end{tabular}

${ }^{\mathrm{a}} \mathrm{P}<0.05$. M, median; IQR, interquartile range; RBC, red blood cells; N/L, neutrophil/lymphocyte; P/L, platelet/lymphocyte; AST, aspartate aminotransferase; TBIL, total bilirubin; A/G, albumin/globulin; GGT, gamma-glutamyl transpeptidase; LDH, lactic dehydrogenase; ALP, alkaline phosphatase; AFP, alpha fetoprotein; CRP, C-reactive protein; PTA, prothrombin activity.

As PVTT is independently associated with distant metastasis of HCC (5-7), in patients with HCC with PVTT, concomitant distant metastasis considerably increases the mortality rate, although the presence of PVTT alone also leads to poor prognosis. In addition, several treatment methods have been used to improve prognosis for patients with HCC with PVTT.
For example, a recent study involving clinical data from 6,474 patients with HCC with PVTT reported that liver resection treatment significantly improved the median overall survival by 1.77 years compared with non-resection treatments (9). In addition, transarterial chemoembolization (TACE) combined with $\gamma$-knife treatment improved survival rates in patients with $\mathrm{HCC}$ 
Table II. Multivariate analysis of the factors associated with distant metastasis.

\begin{tabular}{|c|c|c|c|c|c|}
\hline Variables & Regression coefficient & Assignment & Odds ratio & $95 \% \mathrm{CI}$ & P-value \\
\hline \multicolumn{6}{|l|}{$\mathrm{P} / \mathrm{L}$ ratio } \\
\hline$<3.16$ & & 0 & Normal & & \\
\hline$\geq 3.16$ & & 1 & 2.209 & $0.479-10.191$ & 0.310 \\
\hline \multicolumn{6}{|c|}{ Blood platelet count, $\times 10^{9}$ cells $/ 1$} \\
\hline$<108$ & & & Normal & & \\
\hline$\geq 108$ & & & 1.525 & $0.515-4.519$ & 0.447 \\
\hline \multicolumn{6}{|l|}{$\mathrm{N} / \mathrm{L}$ ratio } \\
\hline$<2.31$ & & 0 & Normal & & \\
\hline$\geq 2.31$ & 1.192 & 1 & 3.294 & $1.104-9.829$ & $0.033^{\mathrm{a}}$ \\
\hline \multicolumn{6}{|c|}{ RBC count, $x 10^{12}$ cells/ 1} \\
\hline$<4.07$ & & 0 & Normal & & \\
\hline$\geq 4.07$ & 1.312 & 1 & 3.712 & $1.677-8.218$ & $0.001^{\mathrm{a}}$ \\
\hline \multicolumn{6}{|l|}{$\mathrm{A} / \mathrm{G}$ ratio } \\
\hline$<1.0$ & & & Normal & & \\
\hline$\geq 1.0$ & & & 2.359 & $0.836-6.658$ & 0.105 \\
\hline \multicolumn{6}{|l|}{$\mathrm{LDH}, \mathrm{U} / 1$} \\
\hline$<218.6$ & & & Normal & & \\
\hline$\geq 218.6$ & & & 0.851 & $0.358-2.022$ & 0.715 \\
\hline \multicolumn{6}{|l|}{ TBIL, $\mu \mathrm{mol} / 1$} \\
\hline$<12.9$ & & & Normal & & \\
\hline$\geq 12.9$ & & & 1.842 & $0.666-5.100$ & 0.239 \\
\hline \multicolumn{6}{|l|}{ ALP, U/1 } \\
\hline$<128.8$ & & & Normal & & \\
\hline$\geq 128.8$ & & & 0.405 & $0.133-1.239$ & 0.113 \\
\hline \multicolumn{6}{|l|}{ CRP, mg/l } \\
\hline$<7.02$ & & 0 & Normal & & \\
\hline$\geq 7.02$ & 1.711 & 1 & 5.537 & $1.461-20.991$ & $0.012^{\mathrm{a}}$ \\
\hline \multicolumn{6}{|l|}{$\mathrm{AST}, \mathrm{U} / \mathrm{l}$} \\
\hline$<118.5$ & & 0 & Normal & & \\
\hline$\geq 118.5$ & 0.912 & 1 & 2.489 & $1.109-5.657$ & $0.029^{\mathrm{a}}$ \\
\hline \multicolumn{6}{|l|}{ GGT, U/1 } \\
\hline$<100$ & & & Normal & & \\
\hline$\geq 100$ & & & 2.450 & $0.716-8.384$ & 0.153 \\
\hline \multicolumn{6}{|l|}{ PTA } \\
\hline$<63$ & & & Normal & & \\
\hline$>63$ & & & 2.282 & $0.759-6.859$ & 0.142 \\
\hline \multicolumn{6}{|l|}{$\mathrm{AFP}, \mu \mathrm{g} / 1$} \\
\hline$<1,000$ & & & Normal & & \\
\hline$\geq 1,000$ & & & 1.578 & $0.898-2.771$ & 0.113 \\
\hline \multicolumn{6}{|c|}{ Tumor thrombus site } \\
\hline Branch & 0.553 & 1 & 1.739 & $1.152-2.547$ & $0.007^{\mathrm{a}}$ \\
\hline Trunk & & 2 & & & \\
\hline Branch + trunk & & 3 & & & \\
\hline
\end{tabular}

${ }^{\mathrm{a}} \mathrm{P}<0.05$. P/L, platelet/lymphocyte; N/L, neutrophil/lymphocyte; RBC, red blood cell; A/G, albumin/globulin; LDH, lactic dehydrogenase; TBIL, total bilirubin; ALP, alkaline phosphatase; CRP, C-reactive protein; AST, aspartate aminotransferase; GGT, gamma-glutamyl transpeptidase; PTA, prothrombin activity; CI, confidence interval.

with PVTT (17). By contrast, metastasis is not easily treated and remains a major cause of treatment failure. To improve the treatment outcomes and prognosis, predicting distant metastasis of HCC with PVTT is crucial. 
Table III. Receiver operating characteristic curve analysis of various individual parameters and the established model in the modeling cohort.

\begin{tabular}{lccccc}
\hline Parameters & $\begin{array}{c}\text { Accuracy } \\
(95 \% \mathrm{CI})\end{array}$ & Sensitivity (\%) & Specificity (\%) & $\begin{array}{c}\text { False positive } \\
\text { value (1-specificity) (\%) }\end{array}$ & $\begin{array}{c}\text { False negative value } \\
(1-\text {-sensitivity) }(\%)\end{array}$ \\
\hline CRP & $0.592(0.549-0.686)$ & 33.54 & 90.24 & 9.76 & 66.46 \\
N/L ratio & $0.562(0.483-0.608)$ & 32.16 & 77.05 & 22.95 & 67.84 \\
RBC count & $0.602(0.519-0.642)$ & 40.21 & 76.07 & 23.93 & 59.88 \\
Tumor thrombus site & $0.589(0.522-0.645)$ & 40.35 & 76.51 & 23.49 & 59.65 \\
AST & $0.574(0.531-0.653)$ & 43.75 & 74.86 & 25.14 & 56.25 \\
Model & $0.731(0.649-0.776)$ & 72.88 & 59.55 & 40.55 & 27.12 \\
\hline
\end{tabular}

N/L, neutrophil/lymphocyte; RBC, red blood cell; CRP, C-reactive protein; AST, aspartate aminotransferase; CI, confidence interval.

Table IV. Receiver operating characteristic curve analysis of individual parameters and the established model in the validation cohort.

\begin{tabular}{lccccc}
\hline Parameters & $\begin{array}{c}\text { Accuracy } \\
(95 \% \text { CI })\end{array}$ & Sensitivity(\%) & Specificity(\%) & $\begin{array}{c}\text { False positive } \\
\text { value (1-specificity) (\%) }\end{array}$ & $\begin{array}{c}\text { False negative value } \\
(1-\text { sensitivity) }(\%)\end{array}$ \\
\hline CRP & $0.594(0.481-0.701)$ & 77.14 & 41.67 & 58.33 & 22.86 \\
N/L ratio & $0.626(0.531-0.730)$ & 85.71 & 39.58 & 60.42 & 14.29 \\
RBC count & $0.502(0.390-0.641)$ & 40.00 & 60.42 & 39.58 & 60.00 \\
Tumor thrombus site & $0.697(0.584-0.795)$ & 62.86 & 75.56 & 24.44 & 37.14 \\
AST & $0.544(0.431-0.654)$ & 94.29 & 14.58 & 85.42 & 5.71 \\
Model & $0.695(0.584-0.791)$ & 65.71 & 68.75 & 31.25 & 34.29 \\
\hline
\end{tabular}

N/L, neutrophil/lymphocyte; RBC, red blood cell; CRP, C-reactive protein; AST, aspartate aminotransferase; CI, confidence interval.

Variables such as high pretreatment platelet counts, numerous or large tumors, microvascular invasion, incomplete capsulation and high preoperative AFP are significantly associated with distant metastasis in HCC (18-21); however, prediction models for the metastasis of HCC with PVTT are not currently available, to the best of our knowledge. In the present study, commonly accessed clinical and biochemical parameters were used to screen the risk factors significantly associated with the distant metastasis of primary HCC with PVTT to establish a convenient early warning system for distant metastasis. The results demonstrated that several biochemical parameters, including $\mathrm{N} / \mathrm{L}$ ratio $\geq 2.31, \mathrm{RBC}$ count $\geq 4.07 \times 10^{12}$ cells $/ 1$, CRP level $\geq 7.02 \mathrm{mg} / 1$, AST level $\geq 118.5 \mathrm{U} / 1$ and tumor thrombus site at branch, were significantly associated with distant metastasis of primary HCC with PVTT. In addition, based on these results, an early prediction system for distant metastasis was proposed, which may be useful for the timely prevention and treatment of distant metastasis of HBV-HCC with PVTT to prolong survival.

Tumor cells produce erythropoietin, which induces the generation of neutrophils (22). Neutrophil generation stimulates active oxygen and cytokines to kill tumor cells; however, it simultaneously inhibits TNF- $\alpha$ production and increases the production of interleukin-1 and endothelial growth factor, which promotes the formation of tumor vessels that results in distant metastasis $(23,24)$. Lymphocytes participate in the tumor immune response and induce apoptosis of tumor cells; thus, they inhibit tumor development and recurrence (25). A high N/L ratio indicates that the number of neutrophils is higher compared with that of lymphocytes; a high N/L ratio is considered a prognostic factor for the progression and metastasis of liver cancer (11-13). In the present study, the N/L ratio was significantly associated with distant metastasis in intermediate to advanced HCC.

Thus far, few studies have addressed the role of RBC count in the prognosis of cancer. A previous study demonstrated that a low preoperative RBC count is an independent risk factor for poor prognosis (overall survival) of primary liver cancer following surgical treatment, which may be explained by the observation that preoperative RBC counts indicate worse Child-Pugh grades in patients, indicating the deterioration of liver function (26). The results of the present study demonstrated that high $\mathrm{RBC}$ counts $\left(\geq 4.07 \times 10^{12}\right.$ cells/l) were independently associated with distant metastasis of HCC with PVTT. Tumor-associated macrophages, which are crucial to the progression and prognosis of cancer (27-29), arise from the spleen (30). Macrophages serve a crucial role in erythropoiesis under pathological conditions (31-33) and promote tumor 


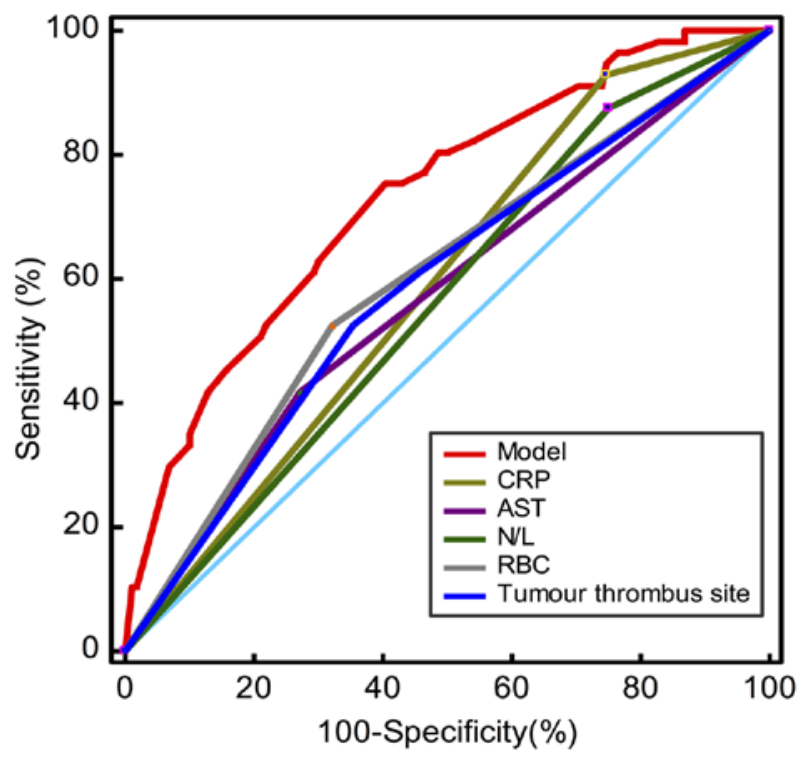

Figure 2. ROC analysis of the established model for distant metastasis in the modeling cohort. The red, dark blue, green, yellow, brown, and gray curves indicate ROC curves of the model, tumor thrombus site, N/L ratio, CRP level, AST level, and RBC count, respectively. The light blue curve indicates the reference line. ROC, receiver operating characteristic; N/L, neutrophi to lymphocyte; CRP, C-reactive protein; AST, aspartate aminotransferase; $\mathrm{RBC}$, red blood cell.

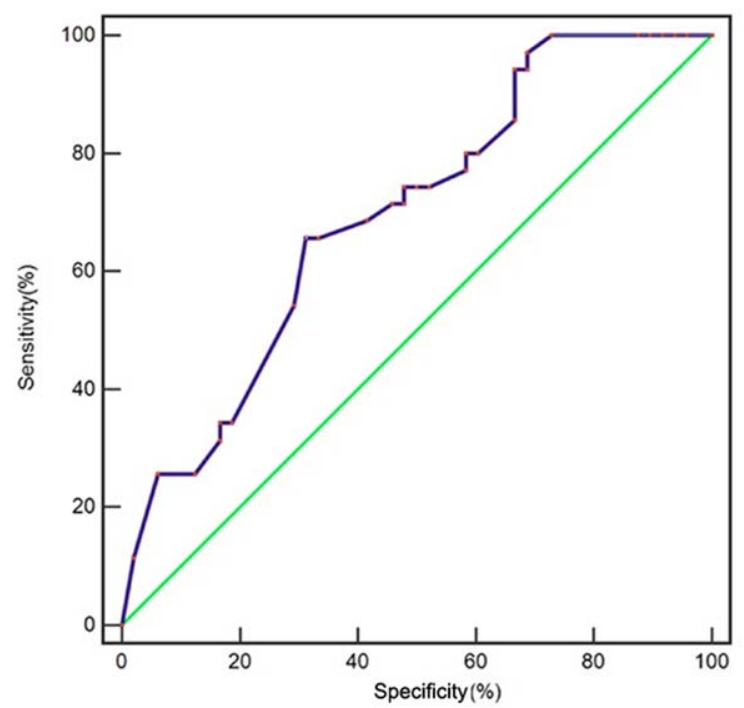

Figure 3. ROC analysis of the developed model for distant metastasis in the validation cohort. The blue curve indicates ROC curves of model. The green curve indicates the reference line. ROC, receiver operating characteristic.

growth, at least partially by stimulating tumor stress-induced erythropoiesis in the spleen (33). This suggests that a high RBC count may be associated with poor prognosis, which may explain the positive association between high RBC counts and distant metastasis of HCC with PVTT in the present study. The role of RBC count in the prognosis of HCC with PVTT needs additional investigation.

CRP is synthesized in hepatic cells and rapidly released into the plasma in the presence of tissue injury, infection and malignant tumors $(34,35)$. CRP is commonly used as a systemic inflammatory marker and is significantly associated

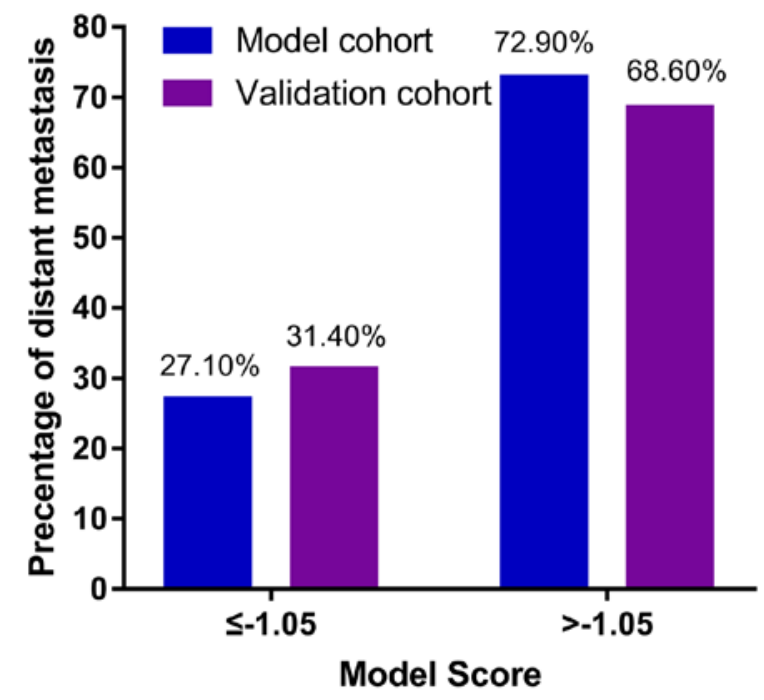

Figure 4. Prediction of distant metastasis in the modeling and validation cohorts.

with poor survival or recurrence of HCC $(36,37)$. CRP level has even been considered an independent predictor of recurrence of HCC with PVTT (38). In the present study, a high CRP level ( $\geq 7.02 \mathrm{mg} / \mathrm{l})$ was an independent risk factor for distant metastasis of HCC with PVTT.

A high AST level is considered to be an independent predictor of poor survival of HCC after treatment $(39,40)$, but a correlation between AST and HCC metastasis has not been reported. In the present study, high AST levels ( $\geq 118.5 \mathrm{U} / \mathrm{l}$ ) were significantly associated with distant metastasis in primary HCC with PVTT.

A previous report demonstrated that in patients with HCC, PVTT in the main trunk or the first branch caused a significantly higher occurrence of intrahepatic metastasis compared with that in other locations (41). By contrast, the results of the present study revealed that PVTT in the branch was significantly associated with distant metastasis of HCC with PVTT. Further study is required to verify this result.

Several prediction models for distant metastasis of HCC following treatment are available $(9,42,43)$; however, to the best of our knowledge, no prediction systems for distant metastasis of HCC with PVTT have been reported thus far. Routine laboratory parameters that are significantly associated with distant metastasis, including $\mathrm{N} / \mathrm{L}$ ratio $\geq 2.31$, RBC count $\geq 4.07 \times 10^{12}$ cells/l, CRP level $\geq 7.02 \mathrm{mg} / \mathrm{l}$, AST level $\geq 118.5 \mathrm{U} / 1$ and tumor thrombus site at branch, were selected and combined to develop an early risk warning model, $\mathrm{Y}=-5.276+1.711 \times \mathrm{CRP}$ $(\mathrm{mg} / \mathrm{l})+1.312 \times \mathrm{RBC}\left(\mathrm{x} 10^{12}\right.$ cells $\left./ \mathrm{l}\right)+1.192 \times \mathrm{N} / \mathrm{L}+0.912 \times \mathrm{AST}$ $(\mathrm{U} / \mathrm{l})+0.553 \times$ tumor thrombus site (branch), to predict distant metastasis in patients with HBV-HCC and PVTT. Patients with a high $\mathrm{Y}$ value (>-1.05) had a considerably higher possibility of distant metastasis compared with those with a lower $Y$ value in the modeling and validation cohorts. In subsequent studies with a sufficiently larger number of patients, the $\mathrm{Y}$ threshold for the formula may be determined more accurately to achieve a more accurate prediction of distant metastasis of HCC with PVTT. 
This model may be beneficial for the identification of patients with HCC with PVTT with a high risk of distant metastasis to actively provide target treatment (such as liver resection, TACE, TACE with sorafenib or radiotherapy) to prevent and treat metastasis as early as possible. Early prediction of metastasis in combination with current or future treatment methods for metastasis may considerably improve the treatment outcomes and prognosis of patients with intermediate to advanced HCC. To the best of our knowledge, similar results have not been reported thus far. Of note, all the variables included in the model are easily assessed in the clinic, which suggests that the established model may be clinically practical and convenient.

This study has several limitations. First, this was a retrospective study involving medical records from only a single medical center, which may have caused bias of patient selection and incompleteness of patient clinical information. For example, Child-Pugh scores are usually used to evaluate hepatic function, whereas in the present study, TBIL, ALP and PTA, which similarly reflect hepatic function, were used instead. Crucial factors associated with metastasis or prognosis such as HBV markers (HBsAg titers, HBV DNA levels, testing positive or negative for $\mathrm{HBeAg}$ and receipt or non-receipt of HBV treatment), des- $\gamma$-carboxy prothrombin, the site (intrahepatic or extrahepatic) of metastasis, HCC treatment history (TACE, transcatheter arterial infusion or chemotherapy) and the time interval between the evaluation of clinical parameters and the diagnosis of distant metastasis were not evaluated in the present study, as complete information for all patients was not available. Consequently, these variables were not included in the analysis. Additionally, the sample size of patients with HCC with PVTT, particularly in the validation cohort, was limited. In addition, diagnosis of HCC with PVTT was only based on clinical imaging diagnosis without gold-standard criteria (such as histological observation), which may have weakened the validation of the established model based on the clinical information of the modeling cohort. A prospective study with a larger sample size conducted at multiple centers and with numerous and comprehensive parameters, including Child-Pugh scores, HBV markers, des- $\gamma$-carboxy prothrombin, the site of metastasis, HCC treatment history, the time interval between the evaluation of clinical parameters and the diagnosis of distant metastasis and survival data, is needed to validate the results of the present study.

In conclusion, the present study revealed the risk factors significantly associated with distant metastasis of HBV-HCC and PVTT and established an early risk warning model for distant metastasis. This model may facilitate the early prediction and treatment of distant metastasis of HBV-HCC with PVTT to improve the prognosis of patients.

\section{Acknowledgements}

Not applicable.

\section{Funding}

This study was supported by the Fund of Special Research of Traditional Chinese Medicine in the Capital City (grant no. 17ZY02), the Fund for Beijing Science and Technology Development of Traditional Chinese Medicine (grant no. JJ2016-14) and the Application of Clinical Features of the Capital City of the Science and Technology Commission (grant no. Z171100001017082).

\section{Availability of data and materials}

The datasets used and/or analyzed during the current study are available from the corresponding author on reasonable request.

\section{Authors' contributions}

$\mathrm{ZY}$ and YJ designed this study. XL and SZ collected, assembled and analyzed data. ML and YZ analyzed and interpreted data. ML and YZ drafted the manuscript. All authors read and approved the final manuscript.

\section{Ethics approval and consent to participate}

This study was approved by the Ethics Committee of Beijing Ditan Hospital, Capital Medical University. As this study was retrospective, informed consent was not required from the patients.

\section{Patient consent for publication}

Not applicable.

\section{Competing interests}

The authors declare that they have no competing interests.

\section{References}

1. Bray F, Ferlay J, Soerjomataram I, Siegel RL, Torre LA and Jemal A: Global cancer statistics 2018: GLOBOCAN estimates of incidence and mortality worldwide for 36 cancers in 185 countries. CA Cancer J Clin 68: 394-424, 2018

2. Liang X, Bi S, Yang W, Wang L, Cui G, Cui F, Zhang Y, Liu J, Gong X, Chen Y, et al: Reprint of: Epidemiological serosurvey of Hepatitis B in China-declining HBV prevalence due to Hepatitis B vaccination. Vaccine 31 (Suppl 9): J21-J28, 2013.

3. Cui Y and Jia J: Update on epidemiology of hepatitis B and C in China. J Gastroenterol Hepatol 28 (Suppl 1): S7-S10, 2013.

4. Jemal A, Bray F, Center MM, Ferlay J, Ward E and Forman D: Global cancer statistics. CA Cancer J Clin 61: 69-90, 2011.

5. Bruix J and Sherman M; Practice Guidelines Committee, American Association for the Study of Liver Diseases: Management of hepatocellular carcinoma. Hepatology 42: 1208-1236, 2015

6. Bruix J and Sherman M; American Association for the Study of Liver Diseases: Management of hepatocellular carcinoma: An update. Hepatology 53: 1020-1022, 2011.

7. Addario L, Tritto G, Cavaglià E, Amodio F, Giannelli E and Di Costanzo GG: Preserved liver function, portal thrombosis and absence of oesophageal varices are risk factors for metastasis of hepatocellular carcinoma. Dig Liver Dis 43: 319-324, 2011.

8. Zhang ZM, Lai EC, Zhang C, Yu HW, Liu Z, Wan BJ, Liu LM, Tian ZH, Deng H, Sun QH and Chen XP: The strategies for treating primary hepatocellular carcinoma with portal vein tumor thrombus. Int J Surg 20: 8-16, 2015.

9. Kokudo T, Hasegawa K, Matsuyama Y, Takayama T, Izumi N, Kadoya M, Kudo M, Ku Y, Sakamoto M, Nakashima O, et al: Survival benefit of liver resection for hepatocellular carcinoma associated with portal vein invasion. J Hepatol 65: 938-943, 2016.

10. European Association for the Study of the Liver. Electronic address: easloffice@easloffice.eu; European Association for the Study of the Liver: EASL 2017 clinical practice guidelines on the management of hepatitis B virus infection. J Hepatol 67: 370-398, 2017. 
11. Okamura Y, Sugiura T, Ito T, Yamamoto Y, Ashida R, Mori K and Uesaka K: Neutrophil to lymphocyte ratio as an indicator of the malignant behaviour of hepatocellular carcinoma. Br J Surg 103: 891-898, 2016.

12. Lu SD, Wang YY, Peng NF, Peng YC, Zhong JH, Qin HG Xiang BD, You XM, Ma L and Li LQ: Preoperative ratio of neutrophils to lymphocytes predicts postresection survival in selected patients with early or intermediate stage hepatocellular carcinoma. Medicine (Baltimore) 95: e2722, 2016

13. Liu X, He L, Han J, Wang L, Li M, Jiang Y, Wang X and Yang Z: Association of neutrophil-lymphocyte ratio and T lymphocytes with the pathogenesis and progression of HBV-associated primary liver cancer. PLoS One 12: e0170605, 2017.

14. Pawarode A, Voravud N, Sriuranpong V, Kullavanijaya P and Patt YZ: Natural history of untreated primary hepatocellular carcinoma: A retrospective study of 157 patients. Am J Clin Oncol 21: 386-391, 1998.

15. Tawada A, Chiba T, Ooka Y, Kanogawa N, Motoyama T, Saito T, Ogasawara S, Suzuki E, Maruyama H, Kanai F, et al: Efficacy of transarterial chemoembolization targeting portal vein tumor thrombus in patients with hepatocellular carcinoma. Anticancer Res 34: 4231-4237, 2014.

16. Villa E, Moles A, Ferretti I, Buttafoco P, Grottola A, Del Buono M, De Santis M and Manenti F: Natural history of inoperable hepatocellular carcinoma: Estrogen receptors' status in the tumor is the strongest prognostic factor for survival. Hepatology 32: 233-238, 2000.

17. Huang M, Lin Q, Wang H, Chen J, Bai M, Wang L, Zhu K, Jiang Z, Guan S, Li Z, et al: Survival benefit of chemoembolization plus Iodine125 seed implantation in unresectable hepatitis B-related hepatocellular carcinoma with PVTT: A retrospective matched cohort study. Eur Radiol 26: 3428-3436, 2016.

18. Byeon J, Cho EH, Kim SB and Choi DW: Extrahepatic recurrence of hepatocellular carcinoma after curative hepatic resection Korean J Hepatobiliary Pancreat Surg 16: 93-97, 2012.

19. Jun L, Zhenlin Y, Renyan G, Yizhou W, Xuying W, Feng X, Yong X, Kui W, Jian L, Dong W, et al: Independent factors and predictive score for extrahepatic metastasis of hepatocellular carcinoma following curative hepatectomy. Oncologist 17: 963-969, 2012.

20. Morimoto Y, Nouso K, Wada N, Takeuchi Y, Kinugasa H, Miyahara K, Yasunaka T, Kuwaki K, Onishi H, Ikeda F, et al: Involvement of platelets in extrahepatic metastasis of hepatocellular carcinoma. Hepatol Res 44: E353-E359, 2014.

21. Lee $\mathrm{CH}$, Lin YJ, Lin CC, Yen CL, Shen $\mathrm{CH}$, Chang CJ and Hsieh SY: Pretreatment platelet count early predicts extrahepatic metastasis of human hepatoma. Liver Int 35: 2327-2336, 2015.

22. Jang WS, Cho KS, Kim MS, Yoon CY, Kang DH, Kang YJ,Jeong WS, Ham WS and Choi YD: The prognostic significance of postoperative neutrophil-to-lymphocyte ratio after radical prostatectomy for localized prostate cancer. Oncotarget 8: 11778-11787, 2017.

23. Duan RD and Nilsson A: Metabolism of sphingolipids in the gut and its relation to inflammation and cancer development. Prog Lipid Res 48: 62-72, 2009.

24. Paramanathan A, Saxena A and Morris DL: A systematic review and meta-analysis on the impact of pre-operative neutrophil lymphocyte ratio on long term outcomes after curative intent resection of solid tumours. Surg Oncol 23: 31-39, 2014.

25. Qin M, Brummel S, Singh KK, Fenton T and Spector SA: Associations of host genetic variants on CD4+ lymphocyte count and plasma HIV-1 RNA in antiretroviral naïve children. Pediatr Infect Dis J 33: 946-952, 2014

26. Xie X, Yao M, Chen X, Lu W, Lv Q, Wang K, Zhang L and Lu F: Reduced red blood cell count predicts poor survival after surgery in patients with primary liver cancer. Medicine (Baltimore) 94: e577, 2015

27. Noy R and Pollard JW: Tumor-associated macrophages: From mechanisms to therapy. Immunity 41: 49-61, 2014.
28. Ries CH, Cannarile MA, Hoves S, Benz J, Wartha K, Runza V, Rey-Giraud F, Pradel LP, Feuerhake F, Klaman I, et al: Targeting tumor-associated macrophages with anti-CSF-1R antibody reveals a strategy for cancer therapy. Cancer Cell 25: 846-859, 2014.

29. Tang X: Tumor-associated macrophages as potential diagnostic and prognostic biomarkers in breast cancer. Cancer Lett 332: 3-10, 2013.

30. Cortez-Retamozo V, Etzrodt M, Newton A, Rauch PJ, Chudnovskiy A, Berger C, Ryan RJ, Iwamoto Y, Marinelli B, Gorbatov R, et al: Origins of tumor-associated macrohages and neutrophils. Proc Natl Acad Sci USA 109: 2491-2496, 2012.

31. Chow A, Huggins M, Ahmed J, Hashimoto D, Lucas D, Kunisaki Y, Pinho S, Leboeuf M, Noizat C, van Rooijen N, et al: $\mathrm{CD} 169+$ macrophages provide a niche promoting erythropoiesis under homeostasis and stress. Nat Med 19: 429-436, 2013.

32. Ramos P, Casu C, Gardenghi S, Breda L, Crielaard BJ, Guy E, Marongiu MF, Gupta R, Levine RL, Abdel-Wahab O, et al: Macrophages support pathological erythropoiesis in polycythemia vera and $\beta$-thalassemia. Nat Med 19: 437-445, 2013.

33. Liu M, Jin X, He X, Pan L, Zhang X and Zhao Y: Macrophages support splenic erythropoiesis in 4T1 tumor-bearing mice. PLoS One 10: e0121921, 2015

34. Eklund CM: Proinflammatory cytokines in CRP baseline regulation. Adv Clin Chem 48: 111-136, 2009.

35. Grivennikov SI, Greten FR and Karin M: Immunity, inflammation and cancer. Cell 140: 883-899, 2000.

36. Liu YB, Ying J, Kuang SJ, Jin HS, Yin Z, Chang L, Yang H, Ou YL, Zheng JH, Zhang WD, et al: Elevated preoperative serum Hs-CRP level as a prognostic factor in patients who underwent resection for hepatocellular carcinoma. Medicine (Baltimore) 94: e2209, 2015.

37. Chan SL, Chan AW, Chan AK, Jian P, Mo F, Chan CM, Mok K, Liu C, Chong CC, Chan AT, et al: Systematic evaluation of circulating inflammatory markers forhepatocellular carcinoma. Liver Int 37: 280-289, 2017.

38. Kim JM, Kwon CH, Joh JW, Ko JS, Park JB, Lee JH, Kim SJ, Paik SW and Park CK: C-reactive protein may be a prognostic factor in hepatocellular carcinoma with malignant portal vein invasion. World J Surg Oncol 11: 92, 2013.

39. Zhang Q, Shang L, Zang Y, Chen X, Zhang L, Wang Y, Wang L, Liu Y, Mao $S$ and Shen Z: $\alpha$-Fetoprotein is a potential survival predictor in hepatocellular carcinoma patients with hepatitis $B$ selected for liver transplantation. Eur J Gastroenterol Hepatol 26: 544-552, 2014

40. Liao W, Zhang J, Zhu Q, Qin L, Yao W, Lei B, Shi W, Yuan S, Tahir SA, Jin J and He S: Preoperative neutrophil-to-lymphocyte ratio as a new prognostic marker in hepatocellular carcinoma after curative resection. Transl Oncol 7: 248-255, 2014.

41. Choi Y, Kim JW, Cha H, Han KH and Seong J: Overall response of both intrahepatic tumor and portal vein tumor thrombosis is a good prognostic factor for hepatocellular carcinoma patients receiving concurrent chemoradiotherapy. J Radiat Res 55: 113-120, 2014.

42. Huang X, Wei W, Ya N, Zeng J, Zeng Y, Ma C, Chi M, Wu Y, Li Y, Huang Y, et al: A mathematical model to predict short-term recurrence and metastasis of primary hepatocellular carcinoma larger than $10 \mathrm{~cm}$ in diameter. Hepatogastroenterology 60: 225-230, 2013

43. Xiang ZL, Zeng ZC, Fan J, Wu WZ, He J, Zeng HY and Tang ZY: A clinicopathological model to predict bone metastasis in hepatocellular carcinoma. J Cancer Res Clin Oncol 137: 1791-1797, 2011.

This work is licensed under a Creative Commons Attribution-NonCommercial-NoDerivatives 4.0 International (CC BY-NC-ND 4.0) License. 